Chamberlatn, N. \& Rainbow, C. (1954). J. gen. Microbiol. 11, 180-190

\title{
The Formation of Diazotizable Amine and Hypoxanthine by a Yeast: Possible Implications in the Biosynthesis of Purines
}

\author{
By N. CHAMBERLAIN aNd C. RAINBOW \\ Department of Applied Biochemistry, University of Birmingham
}

SUMMARY: A diazotizable amine and hypoxanthine accumulate in cultures of Yeast 47 grown in a defined medium containing added methionine and suboptimal biotin. Amine accumulation is depressed by the presence either of added adenine, or of certain amino acids, of which aspartate, norleucine, norvaline and threonine are the most effective. The amine differs from 4-amino-5-imidazolecarboxamide and the corresponding amidine. Spectrophotometric measurements suggest that the amine lacks the completed 6-membered ring structure of the purine skeleton, but it has biological activity in lieu of adenine for the adenine-requiring Yeast 19, and of guanine for a strain of Lactobacillus brevis.

Hypoxanthine substitutes for adenine in the growth of Yeasts 19 and 47, and for adenine + guanine in Lactobacillus brevis, which suggests that hypoxanthine is a bioprecursor of both adenine and guanine. The accumulation of hypoxanthine in cultures of Yeast 47 may thus be the result of a synthetic block, conditioned by biotin deficiency, which prevents the conversion of hypoxanthine to adenine and guanine. The possible relationships between diazotizable amine and hypoxanthine are discussed.

Chamberlain, Cutts \& Rainbow (1952) reported the conditions under which Yeast $\mathbf{4 7}$ formed pigment and accumulated a diazotizable amine in liquid medium. This paper reports a study of the constituents present in aminecontaining concentrates prepared from culture filtrates of Yeast 47.

\section{METHODS}

Test organisms. Three organisms were used:

Saccharomyces cerevisiae (Yeast 47). For growth in a defined medium, Yeast 47 required added biotin and $p$-aminobenzoic acid $(p-\mathrm{AB})$. The $p$-AB was replaceable, at least in part, by relatively large concentrations of adenine, methionine and histidine (Cutts \& Rainbow, 1950).

Schizosaccharomyces octosporus (Yeast 19). For growth in a defined medium, Yeast 19 required added adenine, methionine and histidine, but not $p$-AB (Northam \& Norris, 1951).

Lactobacillus brevis. This was the heterofermentative lactobacillus used by Chamberlain et al. (1952). For growth it required added adenine, guanine and pteroylglutamic acid (PGA).

Cultures of the yeasts were maintained as described by Cutts \& Rainbow (1950). Lactobacillus brevis was maintained as stabs in $10 \%$ malt wort agar supplemented with $0.1 \%$ Difco yeast extract and $0.5 \%$ L-arabinose.

Media. Basal medium A (for Yeast 47) was that described by Cutts \& Rainbow (1950), but biotin was omitted, $0 \cdot 10 \mu \mathrm{g} . p-\mathrm{AB} / \mathrm{ml}$. was added and the $\mathrm{pH}$ adjusted to $4 \cdot 8$. 
Basal medium $\mathrm{B}$ was as $\mathrm{A}$, but $p$-AB was omitted and the following additions $(\mu \mathrm{g} . / \mathrm{ml}$.$) made: D-biotin (0 \cdot 1)$, adenine (50), DL-methionine (100), L-histidine $\mathrm{HCl}(100)$. This medium was used for tests involving Yeast 19 and for Yeast 47 in $p$-AB-free medium.

Basal medium C (for Lactobacillus brevis) was as follows. Per $100 \mathrm{ml}$. final volume, in g.: glucose, $2.0 ; \mathrm{CH}_{3} \mathrm{COONa} .3 \mathrm{H}_{2} \mathrm{O}$ (A.R.) $3 \cdot 2$; casein acid hydrolysate ('vitamin free', Allen and Hanbury) $1.0 ;\left(\mathrm{NH}_{4}\right)_{2} \mathrm{SO}_{4}$ (A.R.) $0.3 ; \mathrm{NaCl}$ (A.R.) 0.5 ; in mg.: L-cystine, 20; DL-tryptophan, 20; $\mathrm{KH}_{2} \mathrm{PO}_{4}$ (A.R.) 50; $\mathrm{K}_{2} \mathrm{HPO}_{4}$ (A.R.) $50 ; \mathrm{MgSO}_{4} .7 \mathrm{H}_{2} \mathrm{O}$ (A.R.) $10 ; \mathrm{MnSO}_{4} .4 \mathrm{H}_{2} \mathrm{O}$ (A.R.) $0.5 ; \mathrm{FeCl}_{3}$ (A.R.) 0.1 ; in $\mu$ g.: thiamine (100); pyridoxin (100); nicotinic acid (100); calcium D-pantothenate (100); riboflavin (50); $p$-AB (20); PGA (10); D-biotin (0.02). Adjustment was made to $\mathrm{pH} \mathrm{6.5,} \mathrm{but,} \mathrm{after} \mathrm{sterilizing} \mathrm{by} \mathrm{heating} \mathrm{in} \mathrm{the}$ autoclave momentarily to $10 \mathrm{lb}$. pressure, the $\mathrm{pH}$ fell to $6 \cdot 2$, the optimum for L. brevis in this medium.

Inocula were prepared as follows:

Yeast 47: grown up in basal medium A containing $0 \cdot 1 \mathrm{~m} \mu \mathrm{g}$. D-biotin/ml,, other details being according to Cutts \& Rainbow (1950).

Yeast 19: as for Yeast 47, but grown up in basal medium B.

Lactobacillus brevis: grown up at $28^{\circ}$ for 16-24 $\mathrm{hr}$. in basal medium C fortified with $10 \mu \mathrm{g}$. of adenine and of guanine $/ \mathrm{ml}$. Harvesting and washing the cells was as above. One drop (c. $20 \mu \mathrm{l}$.) of the final suspension of the washed cells was used $/ 3 \mathrm{ml}$. of medium to inoculate auxanograms. For tube tests, three drops of the final suspension were shaken with $6 \mathrm{ml}$. sterile $\mathbf{0 . 8 5} \%$ saline and one drop of this dilute suspension used to inoculate each tube.

Tube tests ( $6 \mathrm{ml}$. cultures) were carried out as described by Northam \& Norris (1951). Incubation was at $25^{\circ}$ (yeasts) or $28^{\circ}$ (Lactobacillus brevis).

Auxanograms were carried out in the appropriate basal medium at $28^{\circ}$, according to Cutts \& Rainbow (1950), except that, in most cases, substances for test were applied to the agar as circular paper disks cut from papergrams with a sharp cork borer, after the position of the spot chosen for test had been located as indicated below.

Diazotizable amine was determined as described by Chamberlain et al. (1952), but omitting the acetylation procedure.

Chromatography. Chromatograms were run on Whatman no. 4 special chromatography paper (221 in. long) in a glass cabinet maintained at $23-25^{\circ}$, the solvent being $n$-butanol + acetic acid + water (Woiwod, 1949). Test materials were applied as $10 \mu \mathrm{l}$. spots, larger spots (up to $50 \mu \mathrm{l}$.) being obtained, if necessary, by successive applications of $10 \mu \mathrm{l}$. portions, with drying between applications. Under these conditions, the run covered the length of the paper in $12 \frac{1}{2} \mathrm{hr}$., but no ill effects resulted when the papers were left for $18 \mathrm{hr}$. After runs, papers were dried in a current of warm air and compounds then detected as follows: purines by ultraviolet (UV) photography (Markham \& Smith, 1949); amino acids by the ninhydrin reaction (Woiwod, 1949); diazotizable amine by the Bratton \& Marshall (1939) reaction. For the latter reaction the reagents were made up in ethanolic solution to ensure rapid drying after the 
application of each spray to minimize spreading of the spots. The first spray consisted of a mixture of 1 vol. aqueous $4 \mathrm{~N}-\mathrm{HCl}+1$ vol. $0 \cdot 2 \%$ sodium nitrite in $80 \%(\mathrm{v} / \mathrm{v})$ ethanol. After 3 min., $2 \%$ ammonium sulphamate in $75 \%$ $(\mathrm{v} / \mathrm{v})$ ethanol was sprayed on, followed rapidly by $0 \cdot 1 \% \mathrm{~N}$-(1-naphthyl)ethylenediamine $2 \mathrm{HCl}$ in absolute ethanol. Diazotizable amine showed as a pink spot after this treatment.

To examine concentrates of diazotizable amine, three identical spots were chromatographed side by side at one edge of the paper, suitable reference spots (e.g. authentic purines) being included with each run. After the run the complete papergram was examined for purines and two strips, corresponding to the outer spots of concentrate, cut from the paper for further examination, one for amino acids and the other for diazotizable amine. In this way, the positions of amino acids, UV-absorbing substances and diazotizable amine were established on the main papergram, which, being untreated by reagents, was utilizable for biological tests by auxanography.

Spectrophotometry. Measurements were made in $1 \mathrm{~cm}$. quartz cells with the Unicam SP 500 quartz spectrophotometer. Distilled water was used as reference liquid, except when papergram eluates in $0 \cdot 1 \mathrm{j}-\mathrm{HCl}$ were measured. In such cases, a blank eluate in $0 \cdot 1 \mathrm{~N}-\mathrm{HCl}$, obtained from an unoccupied area of the papergram, was used.

'Aldehyde-free' ethanol was prepared by refluxing absolute ethanol for $\mathbf{1 ~ h r}$. in the presence of 2:4-dinitrophenylhydrazine $(1 \mathrm{~g} / 100 \mathrm{ml}$.) and a trace of $\mathrm{H}_{2} \mathrm{SO}_{4}$. The fraction which distilled at $77 \cdot 5-78 \cdot 5^{\circ}$ was collected for immediate use.

\section{EXPERIMENTAL}

\section{Preparation of amine concentrates}

To produce diazotizable amine in quantities sufficient for experimental work, the following procedure was adopted. Two portions (each 1 l.) of medium A fortified with $0.02 \mathrm{~m} \mu \mathrm{g}$. D-biotin and $500 \mu \mathrm{g}$. DL-methionine $/ \mathrm{ml}$., were sterilized (15 lb./sq. in. momentarily) in $6 \mathrm{l}$. Erlenmeyer flasks loosely plugged with cotton-wool. Each flask was inoculated with $6 \mathrm{ml}$. of inoculum of Yeast 47 and incubated at $21^{\circ}$ for 6 days. The pink cell crop was filtered off (Green's paper, no. 503), the filtrates ( $\mathrm{pH} 4 \cdot 4$ ) combined, and a freshly prepared solution of $8 \mathrm{~g}$. mercuric acetate in $150 \mathrm{ml}$. water added slowly with stirring. The precipitate was allowed to settle overnight at $4^{\circ}$ and collected by decantation followed by centrifugation. After washing twice with water, the precipitate was dispersed in $130 \mathrm{ml} .0 \cdot 1 \mathrm{~N}-\mathrm{H}_{2} \mathrm{SO}_{4}$ and decomposed by a current of $\mathrm{H}_{2} \mathrm{~S}$ passed for $1 \mathrm{hr}$. Excess $\mathrm{H}_{2} \mathrm{~S}$ was removed by a current of air, a previously determined volume of barium hydroxide solution added to neutralize the $\mathrm{H}_{2} \mathrm{SO}_{4}$ and the mixed precipitates of $\mathrm{HgS}$ and $\mathrm{BaSO}_{4}$ centrifuged off. The supernatant was evaporated in vacuo below $40^{\circ}$ to $10 \mathrm{ml}$. and treated with $90 \mathrm{ml}$. of 'aldehyde-free' ethanol. After standing for $2 \mathrm{hr}$. at $4^{\circ}$, the precipitate was centrifuged off, ethanol removed from the supernatant by evaporation in vacuo to small volume and the final solution made up to $25 \mathrm{ml}$. This solution (pH 4.0), containing about $50 \%$ of the amine present in the original culture 
filtrate, was used in the subsequent experimental work. The most significant losses of amine in this preparation appeared to occur during the decomposition of the mercury precipitate.

\section{Chromatography of amine concentrates}

Table 1 shows the $\boldsymbol{R}_{\boldsymbol{F}}$ values of diazotizable amine, purine and amino acids detected in amine concentrates by paper chromatography, together with the $\boldsymbol{R}_{F}$ values of authentic reference compounds. The predominant constituents of the amine concentrate thus revealed were:

Diazotizable amine: this spot was positionally distinct from the amino acids and purines present, with the possible exception of guanine. A faint UVabsorbing spot was visible in the amine position, which may have represented the amine itself, or very small amounts of guanine. The first possibility was regarded as the more likely from the spectrophotometric evidence (see below). No other diazotizable material was visible on the papergrams.

The UV-absorbing spot was positionally distinct from amine and corresponded closely with hypoxanthine. Its size and intensity indicated the presence of about $20 \mu \mathrm{g}$. hypoxanthine $/ 30 \mu \mathrm{l}$. amine concentrate. There was some overlap between this spot and the large ninhydrin-positive spot ((c) below). The latter, however, was not UV-absorbing.

The large ninhydrin-positive spot corresponded in position to methionine. Methionine is precipitated by mercuric salts and would therefore be concentrated along with diazotizable amine owing to its presence in the original medium.

Table 1. $R_{F}$ values of substances present in concentrates

Identical conditions for both chromatograms; temperature, 23-25 ${ }^{\circ}$; duration of run, $12 \mathrm{hr}$; ; solvent, $n$-butanol + acetic acid + water; spots : amine concentrate, $30 \mu \mathrm{l}$., reference substances, $20 \mu \mathrm{g}$.

\begin{tabular}{|c|c|c|c|c|}
\hline & \multirow{2}{*}{$\begin{array}{l}\text { Description of } \\
\text { spot }\end{array}$} & \multicolumn{2}{|c|}{ Chromatogram } & \multirow{2}{*}{$\begin{array}{c}\text { Intensity } \\
\text { of } \\
\text { spot }\end{array}$} \\
\hline & & (1) & (2) & \\
\hline $\begin{array}{l}\text { Amine } \\
\text { concentrate }\end{array}$ & $\begin{array}{l}\text { Ninhydrin } \\
\text { positive } \\
\text { Diazotizable } \\
\text { UV-absorbing }\end{array}$ & $\begin{array}{l}0 \cdot 11 \\
0 \cdot 15 \\
0 \cdot 20 \\
0 \cdot 23 \\
0 \cdot 33 \\
0 \cdot 50 \\
0 \cdot 36 \\
0 \cdot 49\end{array}$ & $\begin{array}{l}0 \cdot 13 \\
0 \cdot 17 \\
0 \cdot 22 \\
0 \cdot 25 \\
0 \cdot 34 \\
0 \cdot 52 \\
0 \cdot 38 \\
0 \cdot 50\end{array}$ & $\begin{array}{l}\text { Weak } \\
\text { Weak } \\
\text { Weak } \\
\text { Weak } \\
\text { Weak } \\
\text { Very strong } \\
\text { Strong } \\
\text { Very strong }\end{array}$ \\
\hline $\begin{array}{l}\text { Reference } \\
\text { substances }\end{array}$ & $\begin{array}{l}\text { Guanine } \\
\text { Xanthine } \\
\text { Hypoxanthine } \\
\text { DL-Methionine } \\
\text { Adenine }\end{array}$ & $\begin{array}{l}0 \cdot 39 \\
0 \cdot 42 \\
0 \cdot 49 \\
0 \cdot 50 \\
0 \cdot 61\end{array}$ & $\begin{array}{l}0 \cdot 39 \\
0 \cdot 42 \\
0 \cdot 50 \\
0 \cdot 52 \\
0 \cdot 62\end{array}$ & $\begin{array}{l}\text { Strong } \\
\text { Strong } \\
\text { Strong } \\
\text { Strong } \\
\text { Strong }\end{array}$ \\
\hline
\end{tabular}

Neither amine nor the UV-absorbing constituent (UVAC) was detectable in concentrates prepared similarly from cultures of Yeast 47 which contained optimal biotin (1 $\mathrm{m} \mu \mathrm{g} . / \mathrm{ml}$.) added to the medium. With suboptimal biotin $(0.02 \mathrm{~m} \mu \mathrm{g} . / \mathrm{ml}$.) but no added methionine, both amine and UVAC were formed, 
only in much smaller amounts than when methionine was added. When methionine was not added the only source of methionine was that synthesized by the cells themselves.

\section{Spectrophotometry of amine concentrates}

Absorption curves were measured over the range $200-300 \mathrm{~m} \mu$. on solutions of (i) pure reference substances (10 $\mu \mathrm{g} . / \mathrm{ml}$.); (ii) as (i), but obtained by cutting the appropriate spots from papergrams and eluting with $0 \cdot 1 \mathrm{~N}-\mathrm{HCl}$; (iii) the chief spots from amine concentrates, isolated from papergrams as in (ii).

The results (Table 2) confirmed the identity of UVAC with hypoxanthine and indicated that the diazotizable amine was not contaminated with detectable amounts of guanine. The reference purines and pyrimidines gave characteristic end-absorption at c. $200 \mathrm{~m} \mu$., with peak absorption at 248$284 \mathrm{~m} \mu$. By contrast, diazotizable amine, methionine and histidine showed end-absorption but no peak within the latter range.

\section{Table 2. Values of $\lambda_{\max .}$ for reference substances and constituents of amine concentrate}

Stock solutions of reference substances, $10 \mu \mathrm{g} \cdot / \mathrm{ml}$. in $0.1 \mathrm{~N}-\mathrm{HCl}$, except DL-methionine, $50 \mu \mathrm{g} . / \mathrm{ml}$; ; papergram extracts, $5 \mathrm{ml}$. of eluates in $0.1 \mathrm{~N}-\mathrm{HCl}$ from $5 \times 30 \mu \mathrm{l}$. spots of amine concentrate.

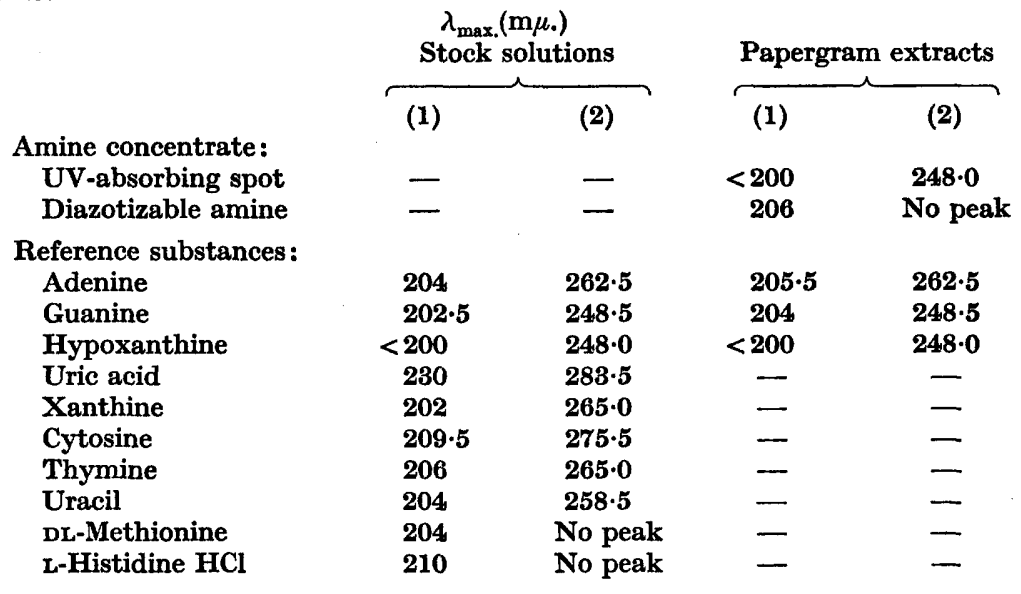

Biological activity of constituents of amine concentrates

Auxanograms. Circles corresponding to constituents of the amine concentrate and to known reference substances (10 $\mu \mathrm{g}$.) were cut from papergrams and tested for biological activity as substitutes for adenine in the growth of Yeasts 19 and 47 and for adenine and guanine in the growth of Lactobacillus brevis. For $L$. brevis, three auxanograms were used, involving medium $\mathrm{C}$ supplemented $(a)$ with $10 \mu \mathrm{g}$. guanine/ml. (to test capacity to substitute for adenine), (b) with $10 \mu \mathrm{g}$. adenine/ml. (to test capacity to substitute for guanine), or (c) with no addition (to test capacity to substitute for adenine + guanine).

The following substances were tested on each plate: adenine, hypoxan- 
thine, guanine, xanthine, DL-methionine, diazotizable amine and UVAC. Positive responses, indicated by zones of growth visible, unless otherwise stated, after $24 \mathrm{hr}$., were observed as follows:

Yeast 47: adenine, hypoxanthine, UVAC.

Yeast 19: adenine, hypoxanthine, UVAC, diazotizable amine; guanine induced a slight response after $48 \mathrm{hr}$.

Lactobacillus brevis: plate $(a)$ adenine, hypoxanthine, UVAC; plate $(b)$ guanine, xanthine, hypoxanthine, UVAC and diazotizable amine; plate (c) hypoxanthine, UVAC.

These results showed that hypoxanthine and UVAC had identical biological properties in these tests. Either substituted for adenine in the growth of Yeasts 19 and 47, and for adenine + guanine in the growth of Lactobacillus brevis. These facts corroborate the spectrophotometric and chromatographic identification of UVAC as hypoxanthine. Diazotizable amine had activity in lieu of adenine for Yeast 19, and for guanine (but not adenine) for $L$. brevis.

Table 3. Biological activity of amine concentrates

Tube tests: growth as Spekker readings after $70 \mathrm{hr}$. Adenine (col. 6) $=100 \mu \mathrm{g} . / \mathrm{ml}$. (yeasts) or $10 \mu \mathrm{g} . / \mathrm{ml}$. (L. brevis); L. brevis tested in presence of (a) $10 \mu \mathrm{g}$. guanine/ml.; (b) $10 \mu \mathrm{g}$. adenine/ml.; (c) no purines; * indicates $10 \mu \mathrm{g}$. each of adenine and guanine $/ \mathrm{ml}$.

\begin{tabular}{|c|c|c|c|c|c|}
\hline & & conc & (ml./6 & sal me & \\
\hline & $\mathbf{0}$ & 0.02 & 0.04 & 0.08 & Adenine \\
\hline & & Gr & pekke & ag) & \\
\hline Yeast 19 & 0.06 & 0.44 & 0.56 & 0.68 & 0.99 \\
\hline Yeast 47 & $0 \cdot 03$ & $0 \cdot 18$ & $\mathbf{0 . 3 2}$ & 0.57 & $1 \cdot 07$ \\
\hline Tatohacillus $(a)$ & 0.01 & 0.01 & 0.02 & 0.02 & 一 \\
\hline Lactooactlus $\{$ (b) & 0.01 & 0.38 & 0.60 & 0.85 & 一 \\
\hline orevns $\quad(c)$ & 0.01 & $0 \cdot 16$ & $\mathbf{0} \cdot \mathbf{3 1}$ & 0.49 & $0.94 *$ \\
\hline
\end{tabular}

Table 4. Antagonism of hypoxanthine by guanine in the growth of Lactobacillus brevis

Tube tests; growth as Spekker readings after $47 \mathrm{hr}$.

Added hypoxanthine $(\mu \mathrm{g} . / \mathrm{ml}$.

\begin{tabular}{|c|c|c|c|c|c|}
\hline & $\mathbf{0}$ & $\mathbf{2 \cdot 5}$ & $5 \cdot 0$ & $10 \cdot 0$ & $20 \cdot 0$ \\
\hline & \multicolumn{5}{|c|}{ Growth (Spekker reading) } \\
\hline Basal medium C & 0.06 & $0 \cdot 19$ & $0 \cdot 30$ & $0 \cdot 45$ & $0 \cdot 64$ \\
\hline $\begin{array}{c}\text { Basal medium C+ } \\
10 \mu \mathrm{g} \text {. guanine } / \mathrm{ml} \text {. }\end{array}$ & 0.07 & 0.08 & 0.08 & 0.09 & 0.09 \\
\hline
\end{tabular}

Tube tests on unseparated amine concentrate confirmed that it substituted for adenine in the growth of Yeasts 19 and 47, and for guanine or for adenine + guanine in the growth of Lactobacillus brevis. Although these responses were expected from the hypoxanthine (UVAC) content of the concentrate, there was an unexpected inability to replace adenine for $L$. brevis (Table 3). The effect of guanine on the growth of $L$. brevis in basal medium $\mathrm{C}$ supplemented with hypoxanthine was therefore studied. The results (Table 4) showed that the growth-promoting activity of hypoxanthine was antagonized by guanine. 
This antagonism may be compared with that found by Fairley \& Loring (1949) to operate for a mutant of Neurospora. The discrepancy that hypoxanthine substituted for adenine in the auxanograms, but not in the tube tests, may be explicable in terms of a concentration gradient operating in favour of the test material in the auxanograms.

\section{Comparison of diazotizable amine with ' carboxamide' and 'carboxamidine'}

The properties of synthetic 4-amino-5-imidazolecarboxamide (carboxamide) and the corresponding amidine (carboxamidine), which are recognized as possible bio-precursors of purines, differed from those of diazotizable amine as follows:

(1) The peak absorptions of the coloured substances formed in the Bratton \& Marshall reaction differed. Measured approximately by means of the Ilford 601-606 series of filters in the Spekker absorptiometer, the maximum absorption of the coloured solution from diazotizable amine occurred with filter 603 , in contrast to filter 604 in the other cases.

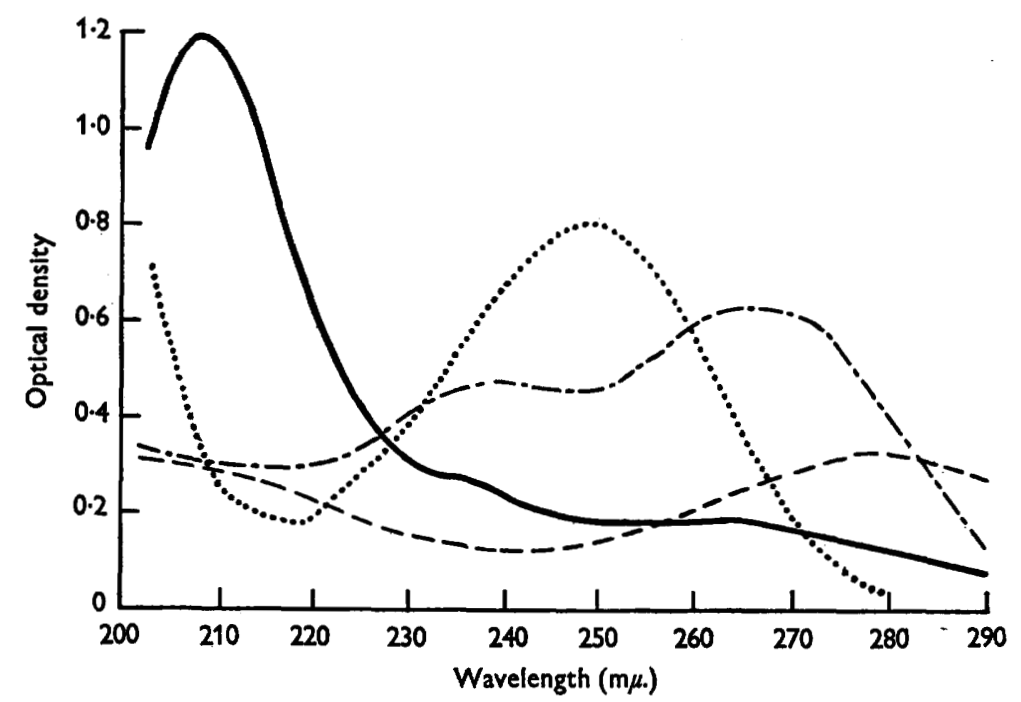

Fig. 1. Ultraviolet absorption curves of solutions in $0 \cdot 1 \mathrm{~N}-\mathrm{HCl}$ of diazotizable amine (-); hypoxanthine (...); carboxamide(-.-.); carboxamidine (---). Concentrations $10 \mu \mathrm{g} . / \mathrm{ml}$., except amine which consisted of $5 \mathrm{ml}$. of extract derived chromatographically from $5 \times 30 \mu l$. samples of amine concentrate.

(2) The ultraviolet absorption curves differed (Fig. 1).

(3) On chromatographing, the $\boldsymbol{R}_{F}$ values obtained were: amine, $\mathbf{0 \cdot 3 6}$; carboxamidine, $0 \cdot 43$; carboxamide, $0 \cdot 47$. For the chromatographic detection of the two latter compounds, the UV photographic technique was applied, since both substances absorbed appreciably at $257 \mathrm{~m} \mu$.

(4) The biological activities of carboxamide and carboxamidine were distinct from those of diazotizable amine. Using small amounts of solid 
substances applied to the surface of auxanograms with a platinium needle, it was shown that: neither carboxamide nor carboxamidine possessed activity as adenine substituents for Yeast 47; carboxamidine, but not carboxamide, substituted for adenine in Yeast 19; carboxamidine substituted for adenine, for guanine or for adenine + guanine in Lactobacillus brevis, although, in each case, the zone of growth was small compared with that induced by a roughly equal quantity of hypoxanthine. This suggested that carboxamidine was required in relatively high concentration. Carboxamide showed no capacity to substitute for purines in the growth of $L$. brevis.

\section{Effect of amino acids and purines on the accumulation of amine in culture filtrates}

Tube tests were used to study the effects of added amino acids and purines on amine formation in an otherwise suitable medium. The results (Table 5) showed that aspartate, threonine and norvaline strongly depressed amine formation, as did norleucine in the early stages. Increased amine formation after $192 \mathrm{hr}$. in the presence of glutamate, lysine and serine was associated with higher final levels of growth, amine formation in terms of unit dry weight of cells being less than, or equal to, the control. There was some suggestion that, after $96 \mathrm{hr}$. , histidine stimulated amine formation.

\section{Table 5. Effect of amino acids and purines on amine formation}

Tube tests in basal medium A containing $500 \mu \mathrm{g}$. DL-methionine $/ \mathrm{ml}$. and $20 \mu \mu \mathrm{g}$. D-biotin/ml. Growth and amine as Spekker readings. Amino acids tested at $500 \mu \mathrm{g}$. (as L-isomer), purines at $50 \mu \mathrm{g} . / \mathrm{ml}$.

\begin{tabular}{|c|c|c|c|c|c|c|}
\hline \multirow{4}{*}{$\begin{array}{l}\text { Basal medium plus } \\
\text { No additions }\end{array}$} & \multicolumn{2}{|c|}{ Growth } & \multicolumn{2}{|c|}{ Amine } & \multirow{2}{*}{\multicolumn{2}{|c|}{$\begin{array}{c}\text { Amine/unit } \\
\text { dry-wt. cells }\end{array}$}} \\
\hline & \multirow{3}{*}{$\begin{array}{l}96 \mathrm{hr} . \\
\overbrace{0.33}\end{array}$} & \multirow{2}{*}{$\begin{array}{l}192 \mathrm{hr} . \\
\text { Spekker }\end{array}$} & $\begin{array}{l}96 \mathrm{hr} . \\
\text { readings }\end{array}$ & \multirow[t]{2}{*}{$192 \mathrm{hr}}$. & & \\
\hline & & & & & & \\
\hline & & $0 \cdot 39$ & $0 \cdot 13$ & $0 \cdot 11$ & 0.66 & 0.45 \\
\hline Amino acids : & & & & & & \\
\hline L-Aspartic acid & $0 \cdot 40$ & $0 \cdot 41$ & 0.03 & 0.02 & $0 \cdot 12$ & $0 \cdot 08$ \\
\hline L-Glutamic acid & 0.47 & 0.59 & $0 \cdot 12$ & $0 \cdot 20$ & $0 \cdot 36$ & 0.45 \\
\hline L-Histidine & $\mathbf{0 . 3 1}$ & $0 \cdot 43$ & $0 \cdot 13$ & $0 \cdot 16$ & 0.67 & 0.56 \\
\hline L-Lysine & $0 \cdot 54$ & $0 \cdot 64$ & $0 \cdot 18$ & $0 \cdot 17$ & $0 \cdot 47$ & 0.35 \\
\hline DL-Norleucine & 0.40 & 0.59 & $0 \cdot 07$ & $0 \cdot 12$ & $\mathbf{0 \cdot 2 7}$ & $0 \cdot 27$ \\
\hline DL-Norvaline & $0 \cdot 37$ & 0.54 & $0 \cdot 05$ & 0.08 & $0 \cdot 21$ & $0 \cdot 19$ \\
\hline DL-Serine & $0 \cdot 37$ & 0.52 & $0 \cdot 12$ & $0 \cdot 13$ & $0 \cdot 51$ & $0 \cdot 29$ \\
\hline DL-Threonine & $0 \cdot 36$ & 0.43 & $0 \cdot 07$ & 0.07 & $0 \cdot 32$ & 0.24 \\
\hline Purines: & & & & & & \\
\hline No additions & $0 \cdot 50$ & - & $0 \cdot 25$ & - & 0.72 & - \\
\hline Adenine & 0.56 & - & $0 \cdot 10$ & - & $0 \cdot 24$ & - \\
\hline Guanine & $0 \cdot 50$ & 一 & $0 \cdot 24$ & - & 0.69 & - \\
\hline Hypoxanthine & $0 \cdot 50$ & - & $0 \cdot 25$ & 一 & $0 \cdot 72$ & - \\
\hline Uric acid & 0.50 & - & $0 \cdot 16$ & - & $0 \cdot 46$ & 一 \\
\hline Xanthine & 0.51 & - & $0 \cdot 23$ & 一 & $0 \cdot 64$ & - \\
\hline
\end{tabular}

The effect of adenine in depressing amine formation (Table 5) was reported by Chamberlain et al. (1952). Of other purines tested, uric acid exerted a slight depressant effect, but added guanine, xanthine and hypoxanthine did not affect amine formation. 
The partial prevention of amine formation by norleucine was probably due to competitive interference with methionine utilization (cf. Porter \& Meyers, 1945; Lampen \& Jones, 1947; Harding \& Shive, 1948). For concentration ratios of DL-norleucine to DL-methionine between 0.5 and $2 \cdot 0$, when the concentration of norleucine was increased fourfold from $250 \mu \mathrm{g} . / \mathrm{ml}$., the concentration of amine formed remained fairly constant. Since Yeast 47 did not require added methionine for growth when $p$-AB was present, presumably then synthesizing its own requirements, the norleucine methionine antagonism should be overcome eventually in favour of methionine, as was found to be the case (Table 5).

Since no similar competitive interference with methionine utilization was demonstrable for norvaline and aspartate, the prevention of amine accumulation by these amino acids was not explicable on the above grounds.

\section{DISCUSSION}

In view of the accumulation of hypoxanthine as well as diazotizable amine in cultures of Yeast $\mathbf{4 7}$ grown in defined medium containing methionine and suboptimal biotin, some modification of the scheme proposed by Chamberlain et al. (1952) is necessary. In particular, it seems that the block caused by biotin deficiency occurs after completion of the purine skeleton (as hypoxanthine), the essential systems affected being either or both of those by which hypoxanthine is transformed to adenine and guanine. The results with Lactobacillus brevis, which cannot accomplish the inter-conversion adenine $\rightleftharpoons$ guanine, indicate that hypoxanthine (or a derivative) is a common precursor of adenine and guanine. The same may be true for Yeasts 19 and 47 , but less evidently so, because both organisms convert adenine to guanine (via hypoxanthine?), only the reverse process being impaired.

As the formation of adenine and guanine from hypoxanthine involves amination, it is interesting to note that Lichstein \& Umbreit (1947) reported the deaminases of aspartic acid, serine and threonine to be specifically activated by biotin. In the case of aspartic acid, the reverse (amination) reaction was also activated by biotin. It is possible to explain our biotinconditioned synthetic block in the light of these findings. Thus if aspartate (and/or threonine) are amino group donors in the amination of hypoxanthine to adenine (and possibly guanine), then failure to synthesize aspartate by amination (a biotin-dependent reaction) would explain hypoxanthine accumulation in our experiments.

Assuming that amine and hypoxanthine are intermediates related by a simple biosynthetic chain, the following scheme is possible:

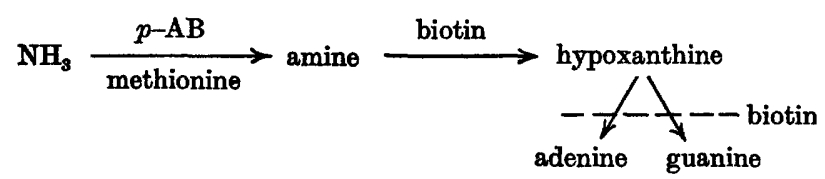

In such a sequence in the cell, the actual substances transformed might be derivatives (e.g. ribosides or ribotides) of the amine and purine molecules 
indicated. The evidence that diazotizable amine is intermediate in purine biosynthesis is: $(a)$ the circumstances under which amine accumulates, the prevention of that accumulation by added adenine and other indirect evidence (see also Chamberlain et al. 1952); (b) the biological activity of amine as a substituent for adenine (Yeast 19) and guanine (Lactobacillus brevis). There are, however, a number of objections to such a scheme. Thus, amine did not substitute for adenine in the auxanograms of Yeast 47, whereas hypoxanthine did. Again, if it is permissible to attempt an interpretation of the sequence of events in $L$. brevis in terms of the scheme, the failure of amine to substitute for adenine + guanine, whereas it will do so for guanine, is not immediately explicable if hypoxanthine (which will substitute for adenine + guanine in L. brevis) is intermediate between amine and guanine. A further obstacle is to explain the accumulation of two intermediates in the same chain as a result of biotin deficiency. Possibly biotin is also concerned with the conversion of amine to hypoxanthine, in which case the step must be insensitive to biotin deficiency relative to the processes responsible for utilizing hypoxanthine.

Following from the above, it is interesting that amine appears to lack the complete purine ring structure. The spectrophotometric evidence suggests that the pyrimidine ring is lacking, since amine solutions do not show the peak absorption between 245 and $285 \mathrm{~m} \mu$., characteristic of the purines and pyrimidines examined. Carbon-6 of the purines is known to be donated by $\mathrm{CO}_{2}$ (Sonne, Buchanan \& Delluva, 1946) the fixation of which is known, in other contexts, to be associated with biotin-requiring systems. It is thus possible that amine may lack carbon- 6 of the purine skeleton.

If biotin is not implicated between amine and hypoxanthine in the above scheme, it is necessary to suppose that this conversion is freely reversible, so that the accumulation of hypoxanthine, resulting from biotin-deficiency, would lead to a parallel accumulation of amine.

If amine is not in the biosynthetic chain which yields hypoxanthine, it could arise by a side reaction from hypoxanthine and, in turn, react with cell constituents to form the red pigment always found in cultures in which amine accumulated:

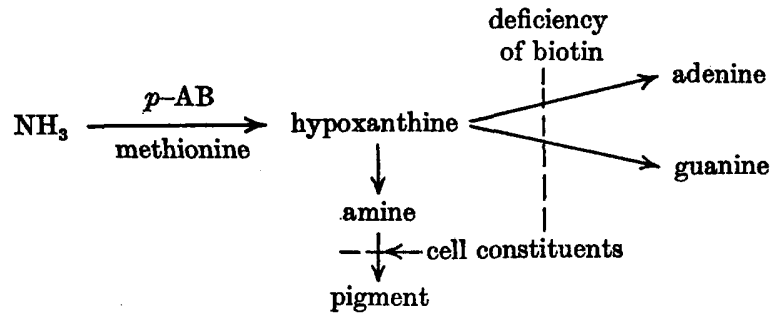

This hypothesis is favoured because, taken together with the suggested roles of aspartate and threonine as amino group donors for the conversion of hypoxanthine to adenine and guanine, it provides a simple explanation of the prevention of amine accumulation by added aspartate and threonine, the 
presence of these amino acids permitting normal amination of hypoxanthine, which thus does not accumulate.

The observations of Friedman \& Gots (1952) may also be relevant to this explanation. They showed that hypoxanthine and adenine could be reduced to diazotizable amines. Hypoxanthine yielded a mixture of two amines, one of which was carboxamide; the other, and that from adenine, resemble our amine sufficiently in their UV absorption spectra to suggest that they may be related substances.

We are indebted to Dr R. H. Nimmo-Smith for gifts of 4-amino-5-imidazolecarboxamide and the corresponding amidine and to the Department of Scientific and Industrial Research for a grant to one of us (N.C.).

\section{REFERENCES}

Bratton, A. C. \& Marshall, E. K. (1939). A new coupling component for sulphanilamide determination. J. biol. Chem. 128, 537.

Chamberlain, N., Cutts, N. S. \& Rainbow, C. (1952). The formation of pigment and arylamine by yeasts. J. gen. Microbiol. 7, 54 .

CutTs, N. S. \& RaInbow, C. (1950). Studies of a yeast exacting towards $p$-aminobenzoic acid. J. gen. Microbiol. 4, 150.

Fairley, J. L. \& Loring, H. S. (1949). Growth-promoting activities of guanine, guanosine, guanylic acid, and xanthine for a purine-deficient strain of Neurospora. J. biol. Chem. 177, 451.

Friedman, S. \& Gots, J. S. (1952). The production of diazotizable amines by a simple degradative reaction of purines. Arch. Biochem. Biophys. 39, 254.

Harding, W. M. \& Shive, W. (1948). Biochemical transformations as determined by competitive anologue-metabolite growth inhibitions. VIII. An interrelationship of methionine and leucine. J. biol. Chem. 174, 743.

LAMPEN, J. O. \& Jones, M. J. (1947). Studies on the sulphur metabolism of Escherichia coli. II. Interrelations of norleucine and methionine in the nutrition of Escherichia coli and of a methionine-requiring mutant of Escherichia coli. Arch. Biochem. 13, 47.

Lichstein, N. C. \& Umbreit, W. W. (1947). Biotin activation of certain deaminases. J. biol. Chem. 170, 423.

Markham, R. \& SMith, J. D. (1949). Chromatographic studies of nucleic acids. I. A technique for the identification and estimation of purine and pyrimidine bases, nucleosides and related substances. Biochem. J. 45, 294.

Northam, B. E. \& Norris, F. W. (1951). Growth requirements of Schizosaccharomyces octosporus, a yeast exacting towards adenine. J. gen. Microbiol. 5, 502.

Porter, J. R. \& Meyers, F. P. (1945). Amino acid interrelationships in the nutrition of Proteus morganii. Arch. Biochem. 8, 169.

Sonne, J. C., Buchanan, J. M. \& Delluva, A. M. (1946). Biological precursors of uric acid carbon. J. biol. Chem. 166, 395.

Worwod, A. J. (1949). A technique for examining large numbers of bacterial culture filtrates by partition chromatography. J. gen. Microbiol. 3, 312. 